\title{
Urban Mining of Fuel Gases via Low Temperature Pyrolysis of Post-Consumer High Density Polyethylene Wastes
}

\section{${ }^{* 1}$ NWADINIGWE, CA; ${ }^{2}$ SURMA, N; ${ }^{1}$ ALUMONA, TN; ${ }^{1}$ EZEOFOR, CC; ${ }^{3}$ LAWAL, AM}

${ }^{I}$ Department of Pure and Industrial Chemistry, University of Nigeria, Nsukka, Enugu State, Nigeria

${ }^{2}$ Department of Chemistry, University of Agriculture, Makurdi P.M.B. 2373 Makurdi, Benue, State Nigeria

${ }^{3}$ Department of Chemistry, Federal University, P.M.B. 1001, Gusau, Zamfara State, Nigeria

"Corresponding Author Email: chukwuemeka.nwadinigwe@unn.edu.ng

\begin{abstract}
Low temperature pyrolysis of high density polyethylene (HDPE) wastes was studied by adapting a cylindrical pressure cooking pot of height $30.00 \mathrm{~cm}$ with an internal diameter of $31.50 \mathrm{~cm}$. The pyrolysis reaction was carried out with and without catalysts. The gases evolved during the pyrolysis were collected in Tedlar bags and analysis was done using a Buck 530 Gas chromatograph. Results when the pyrolysis was without catalyst, showed aliphatic hydrocarbons in the range of $\mathrm{C}_{1}-\mathrm{C}_{10}$ with a total concentration of $87.0114 \mathrm{ppm}$ and $93.9733 \mathrm{ppm}$ at $200{ }^{\circ} \mathrm{C}$ and 350 ${ }^{\circ} \mathrm{C}$ respectively. The pyrolysis was repeated under catalytic influence of zeolite using catalyst/sample ratios of 1:8 and $1: 16$ at $150^{\circ} \mathrm{C}$ and $250^{\circ} \mathrm{C}$. Results showed that the total yield of gases for HDPE under the zeolitic effect at temperatures of $150{ }^{\circ} \mathrm{C}$ and $250{ }^{\circ} \mathrm{C}$ using catalyst/sample ratio of $1: 8$ to be $159.4613 \mathrm{ppm}$ and $394.4499 \mathrm{ppm}$ respectively. The corresponding values obtained at $150{ }^{\circ} \mathrm{C}$ and $250{ }^{\circ} \mathrm{C}$ using catalyst/sample ratio of $1: 16$ were $595.8016 \mathrm{ppm}$ and $724.0983 \mathrm{ppm}$ respectively. The hydrocarbon gases revealed $\mathrm{C}_{1}-\mathrm{C}_{10}$ aliphatic hydrocarbons which can be fractionated into fuel gases $\left(C_{1}-C_{4}\right)$, gasoline range gases $\left(>C_{7}\right)$ and organic solvents $\left(C_{5}-C_{7}\right)$.
\end{abstract}

\section{DOI: https://dx.doi.org/10.4314/jasem.v22i6.18}

Copyright: Copyright $(92018$ Nwadinigwe et al. This is an open access article distributed under the Creative Commons Attribution License (CCL), which permits unrestricted use, distribution, and reproduction in any medium, provided the original work is properly cited.

Dates: Received: 26 April 2018; Revised: 12 June: 2018; Accepted: 30 June 2018

Key words: Pyrolysis, high density polyethylene, zeolite, aliphatic hydrocarbon.

Ethylene, with crude oil and natural gas as precursors, is one of the six major petrochemical industrial raw materials. It can be polymerized into high or low density (HDPE or LDPE) polyethylenes. These differ slightly in molecular structure depending on operating conditions, particularly pressure. Both HDPE and LDPE are thermoplastic, tough with a slightly waxy feel, and widely used for the manufacture of domestic wax, bottles, packing films and all kinds of industrial components using various methods of moulding.

Current research efforts however have tended to tilt quite heavily towards the precursor crude oil and natural gas by way of exploration Oriji and Ekpeti (2016), refining Hossien and Mohammed (2017), Badmus et al., (2013), fractionating Nwadinigwe et al., (2016), analysis Nwadinigwe and Alumona (2017), and environmental aspects Ite and Ibok (2013) with attendant waste proliferation.
This work focuses on low temperature pyrolysis of post-consumer high density polyethylene wastes in other to recovery fuel gases from them.

$$
\begin{aligned}
& \mathrm{C}_{\mathrm{n}} \mathrm{H}_{2 n+1}+\frac{3_{n+1}}{2} \mathrm{O}_{2} \stackrel{\text { Flame }}{\longrightarrow} \mathrm{CO}_{2(n+1)} \mathrm{H}_{2} \mathrm{O}, \Delta \mathrm{H}=\text { exotherm } \\
& \mathrm{n}-\mathrm{C}_{5} \mathrm{H}_{12}+8 \mathrm{O}_{2} \rightarrow 5 \mathrm{CO}_{2}+6 \mathrm{H}_{2} \mathrm{O}, \Delta H=-845 \mathrm{~K} \mathrm{cal}(2)
\end{aligned}
$$

The enormous energy evolved is the reason why alkanes are used as fuels.

Detailed chemical mechanism for the conversion of LDPE and HDPE to hydrocarbons is still a matter of conjecture. Loss of hydrogen atom followed by hemolytic $\beta$-fission of a $\mathrm{C}$ - $\mathrm{C}$ bond could be a possible pathway, Nwadinigwe, (2012).

\section{MATERIALS AND METHODS}

Collection and preservation of Materials: The high density polyethylene (HDPE) waste which consisted of post-consumer pharmaceutical, cosmetic, and 
yoghurt bottles, was collected from refuse dumping sites around Makurdi town, Benue State of Nigeria. The samples were washed thoroughly using detergents and rinsed properly with de-ionized water, then dried to remove moisture. The dried samples were then reduced to smaller bits to increase the surface area as described by Abdulkareem et al., (2014). The zeolite catalyst employed for this work was a Sigma Aldrich Company product and is shown by analysis to be composed of aluminum and silicon. Scanning election microscopy (SEM) images of the zeolite catalyst were obtained at magnifications of $1000 \mathrm{x}, 2500 \mathrm{x}, 4000 \mathrm{x}$, $7,500 \mathrm{x}, 10000 \mathrm{x}$, and $15000 \mathrm{x}$ respectively. From the SEM images it was deduced that the zeolite particle size range within $5 \mu-80 \mu$. In further characterizing the zeolite catalyst SEM was combined with Atomic Absorption spectrometry (AAS) in the detection of the metal composition. Analysis indicated the presence of aluminum $6.301 \mathrm{ppm}$ and silicon $0.722 \mathrm{ppm}$ metals.

Experimental procedures: A Presto pressure cooking pot made of stainless steel (with dimensions of height $30.00 \mathrm{~cm}$ and an internal diameter of $31.50 \mathrm{~cm}$ ) was converted to a fixed bed reactor and adapted for the reaction Smith (1993). The cover had an outlet tube at the top for collection of the evolved gases. The reactor was effectively lagged with a fire blanket and placed in a sand bath constructed with iron sheets for good heat retention. The reactor fitted in the sand bath was heated with three Mekker burners in order to attain the required temperatures which were controlled by means of a thermocouple. Tedlar bags were used for collection of the evolved gases. The collected gases were sent to a gas chromatograph for analysis.

Low Temperature Thermal cracking of HDPE: $1.5 \mathrm{Kg}$ of the HDPE samples were crushed and stuffed in the reactor and heated for about 3 hours until the temperature reached $350{ }^{\circ} \mathrm{C}$. The reaction temperature was monitored and controlled by means of a thermocouple. The gases started evolving after $1 \frac{1}{2}$ hours into the pyrolysis and this was evident as the tedlar gas sampling bags began to swell (at a temperature of about $120^{\circ} \mathrm{C}$ ). The gas samples were collected at $200{ }^{\circ} \mathrm{C}$ and $350{ }^{\circ} \mathrm{C}$ and after the evolution of gases, the system was allowed to cool before the reactor was opened. The residue in the reactor was collected and weighed. The gases which were collected in labeled tedlar gas sampling bags were kept for gas chromatographic analysis. This was done according to the method described by Ademiliyi and Adebayo (2007).

Catalytic Cracking of HDPE: Two catalyst/sample ratios (1:8 and 1:16) were investigated in the catalyzed pyrolysis as described by Osueke and Ofondu (2011) with slight modifications. The sample (polymer material $200 \mathrm{~g}$ ) was placed at the bottom while the catalyst material was arranged in sandwich layers within the polymer sample Abdulkareem et al.,( 2014). The reactor was covered and heating commensed. After 30 minutes into the reaction (at 120 ${ }^{\circ} \mathrm{C}$ ) evolution of gases started slightly and after $1 \frac{1}{2}$ hours at $250{ }^{\circ} \mathrm{C}$ the system was shut down. The gases which were collected at $150{ }^{\circ} \mathrm{C}$ and $250{ }^{\circ} \mathrm{C}$ in labeled tedlar bags were analyzed. The system was allowed to cool down before the reactor was opened. The residue after each run was collected and weighed.

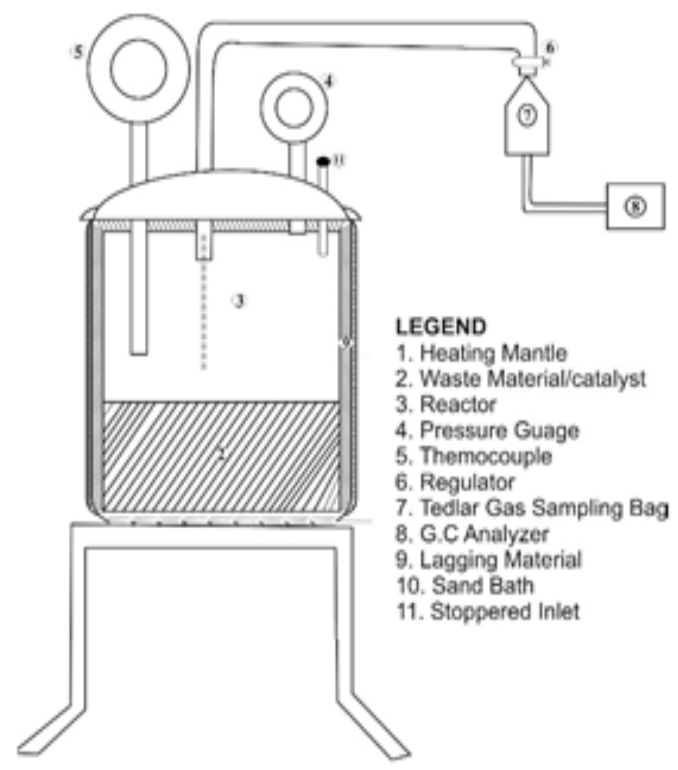

Fig. 1 layout of the process

Gas chromatographic Analysis: The gaseous products obtained from pyrolysis of HDPE with and without the effect of catalysts were characterized using a Buck 530 gas chromatograph and HP- 88 column $(10 \mathrm{~m} / 0.25$ $\mathrm{mm}$ thin thickness). Injection volume was $10 \mu \mathrm{L}$ with helium as the mobile phase and flame ionization detector (FID), injection and detection temperatures were $250{ }^{\circ} \mathrm{C}$ and $280^{\circ} \mathrm{C}$ respectively Gary (1979).

\section{RESULTS AND DISCUSSION}

The high density waste polyethylene employed for this work consisted of a mixture of polyethylene pharmaceutical, cosmetic, and yoghurt waste bottles. The weight obtained at the end of the pyrolysis reaction was $900 \mathrm{~g}$ while $110 \mathrm{~g}$ and $120 \mathrm{~g}$ were obtained at the end of the catalytic pyrolysis at catalyst/sample ratios of 1:8 and 1:16 respectively.

Comparative composition of the gases evolved from pyrolysis of waste $\mathrm{HDPE}$ at $200{ }^{\circ} \mathrm{C}$ and $350{ }^{\circ} \mathrm{C}$ is represented in Fig 2. Detailed chemical mechanism for the conversion of HDPE to low molecular weight 
hydrocarbons is still a matter of conjecture. Loss of a hydrogen atom followed by the homolytic $\beta$ - fission of a $\mathrm{C}-\mathrm{C}$ bond could be a plausible pathway Nwadinigwe (2012).

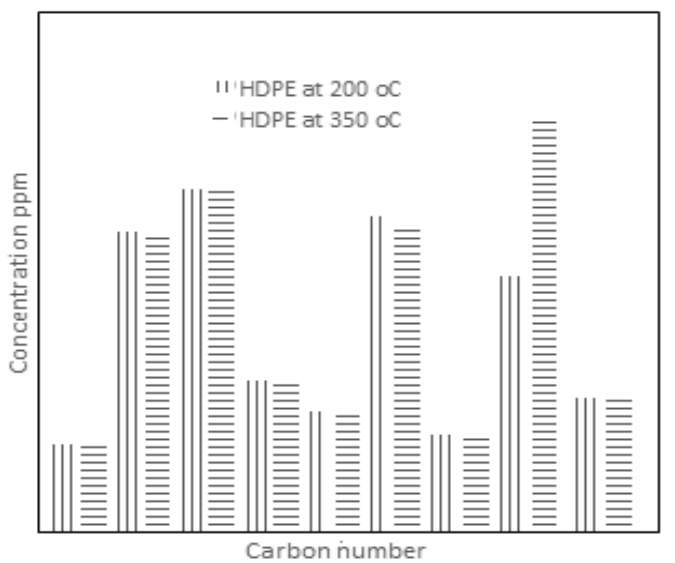

Fig 2: Composition of gas obtained from pyrolysis of waste $\mathrm{HDPE}$ at $200^{\circ} \mathrm{C}$ and $350^{\circ} \mathrm{C}$

It is observed from the results that the total yield of gases obtained at $350^{\circ} \mathrm{C}$ is higher than the total yield obtained at $200{ }^{\circ} \mathrm{C}$. This shows that the temperature affects both the reaction time and yield of liquid, as well gaseous products. High temperature thus speeds up the reaction and lowers the reaction time Sacchin and Singh (2011).

From the pyrolysis reaction carried out at $200{ }^{\circ} \mathrm{C}$, the prominent percentage composition of carbon atoms were observed in $C_{2} 14.4367 \mathrm{ppm} ; \mathrm{C}_{3} 16.5059 \mathrm{ppm}$; $\mathrm{C}_{4} 7.2777 \mathrm{ppm} ; \mathrm{C}_{6} 15.1965 \mathrm{ppm}$ and $\mathrm{C}_{8} 12.3268 \mathrm{ppm}$. On the other hand results of pyrolysis reaction performed at $350{ }^{\circ} \mathrm{C}$ gave the prominent composition in $\mathrm{C}_{2} 14.3430 \mathrm{ppm} ; \mathrm{C}_{3} 16.4367 \mathrm{ppm} ; \mathrm{C}_{6} 14.8305 \mathrm{ppm}$ and $\mathrm{C}_{8} 19.9588 \mathrm{ppm}$. This result shows that useful gases were obtained via pyrolysis of HDPE at temperatures of $200{ }^{\circ} \mathrm{C}$ and $350{ }^{\circ} \mathrm{C}$. The yields of the gases however increased with higher temperature. $\mathrm{C}_{2}$ carbon atom is one of the dominant components observed. This could be explained with the structure and degradation pattern of polyethylene because it is built up from $\mathrm{C}_{2}$ monomer Borsidi et al.,(2011).

In figure 3 is presented the gaseous composition when the catalyst/sample ratio is $1: 8$. The yield of gases was higher at $250{ }^{\circ} \mathrm{C}$ compared with the gases collected at $150^{\circ} \mathrm{C}$. From the results presented in fig 4 , the reaction also occurred at $150^{\circ} \mathrm{C}$ and $250{ }^{\circ} \mathrm{C}$ at catalyst/sample ratio of 1:16, here too the gas yield was higher at 250 ${ }^{\circ} \mathrm{C}$ than what was obtained at $150{ }^{\circ} \mathrm{C}$. It became clear that the effect of the zeolite catalyst on the pyrolysis of HDPE on the yields and distribution of the products were less significant with the increasing temperature, this is in agreement with results obtained by Miskolczi, (2004).

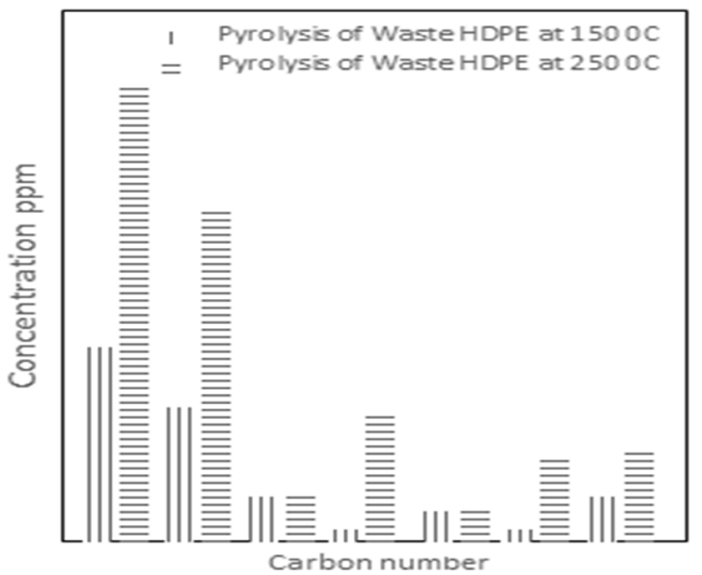

Fig 3: Composition of Gases Obtained From Catalytic Pyrolysis of Waste HDPE at $150{ }^{\circ} \mathrm{C}$ and $250{ }^{\circ} \mathrm{C}$ Using Catalyst/Sample Ratio 1:8 (Reaction with zeolite catalyst)

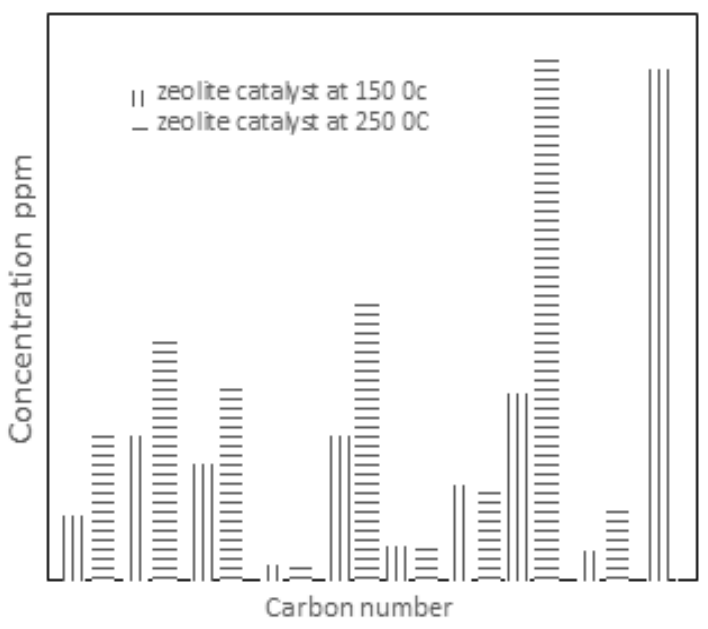

Fig 4: Composition of gases obtained from catalytic pyrolysis of waste HDPE Using zeolite catalyst at $150^{\circ} \mathrm{c}$ and $250^{\circ} \mathrm{c}$ with catalyst/sample ratio of 1:16

The composition of gas was analysed by the gas chromotograph and the results are already presented in fig 3 and in fig 4 . The dominant components were in $\mathrm{C}_{1} 66.1801 \mathrm{ppm} ; \mathrm{C}_{3} 45.2271 \mathrm{ppm} ; \mathrm{C}_{4} 15.0015 \mathrm{ppm}$ while in fig 4 , the dominant components were observed in $\mathrm{C}_{1} 29.1893 \mathrm{ppm} ; \mathrm{C}_{2} 63.6581 \mathrm{C}_{3} 51.7032$ ppm; $\mathrm{C}_{5} 64.0931 \mathrm{ppm} ; \mathrm{C}_{7} 42.4603 \mathrm{ppm} ; \mathrm{C}_{8} 82.7655$ $\mathrm{ppm}$ and $\mathrm{C}_{10} 226.0256 \mathrm{ppm}$. In every case one of the dominant components that was observed is $\mathrm{C}_{2}$. Its occurrence has already been explained in terms of the structure and degradation pattern of polyethylene because it is built up from $\mathrm{C}_{2}$ monomers Borsidi et al.,( 2011). This result shows that lighter hydrocarbon increased in concentrations over what was obtained thermally which is in accordance with the expectation that the catalyst should promote breaking down of 
polymer feed to lighter fractions as compared with the pyrolysis reaction without the influence of the catalyst.

From the result it is observed generally that the zeolite catalyst favoured production of gaseous products. This agrees with results obtained by Lin and Yang, (2005) who conducted catalytic reactions of post-consumer polymer waste over fluidized cracking catalyst for production of hydrocarbons. In their result they obtained $\mathrm{C}_{1}-\mathrm{C}_{3}$ and $\mathrm{C}_{5}-\mathrm{C}_{9}$ hydrocarbons. It can be seen from the results that the total concentration of gases obtained at $150{ }^{\circ} \mathrm{C}$ was lower than the total concentration of gases obtained at $250{ }^{\circ} \mathrm{C}$ when the results in Fig 3 and Fig. 4 are compared.

This could be explained thus the effect of temperature on the reaction time for pyrolysis of HDPE increases with increase in temperature because high temperature supports the easier cleavage of bonds and thus speeds up reaction. However, HDPE is a long linear polymer chain with low branching and high crystallanity led to high strength properties and thus required time for decomposition. Sacchin and Singh (2011).Also, comparing the total components of gases in Fig 3 and Fig 4, it is obvious that higher yields were obtained in figure 4 .

Conclusion: This study demonstrates that low temperature pyrolysis of high density polyethylene whether catalyzed or uncatalyzed is effective method that could allow reasonable conversion of waste polyethylene to useful fuel gases and at the same time reduces the bulk size of the waste. The fuel gases contained mainly aliphatic hydrocarbons which can be fractionated into gaseous fuels, gasoline range products and other organic solvents. The use of low temperature pyrolysis reduced cost by lowering energy input and still generated useful hydrocarbon gases.

\section{REFERENCES}

Abdulkareem, SA; Eleburuike, NA; Amoloye, TO (2014) Comparison of Fuel oil from Thermal Cracking and Catalytic cracking of high density polyethylene. J. Chem. Soc. Nigeria 39 (1): 103106.

Ademililuyi, T; Adebayo, TA (2007). Fuel Gases from Pyrolysis of Waste Polyethylene Sachets. J. Appl. Sci. Environ. Man. 11 (2): 21-26.

Badmus, IF; Fagbene, RO; Oye-Wolu, MO (2013) Fuel Mix and Energy Utilization Analysis of Kaduna Refining Company, Nigeria. Inter. J. Engineer. 3 (3): 190-199.
Bordi, N; Miskolczi, N; Angyal, A; Bartha, L; Kohan, J; and Lengyel, A (2011) Hydrocarbons obtained by Pyrolysis of Contaminated waste plastics. $45^{\text {th }}$ International petroleum conference. Bratislava Slovak Republic 1-9.

Gary, DC (1979) Analytical Chemistry (2 ${ }^{\text {nd }}$ Edition) John Wiley and Sons, New York London. 180-184.

Hossien, Z; Mohammed, AS (2017). Enhanced Gas Recovery with Carbon (iv) oxide Sequestration in Water Drive Gas Condensate Reservoir: a case study of real gas field. J. Petrol. Sci. Technol. 7 (2): 3-11.

Ite, AE; Ibok, UJ (2013). Gas flaring and venting associated with petroleum exploration and production in the Nigeria's Niger Delta. J. Environ. Protect.1 (4): 70-77.

Lin, YH; Yang, HF (2005). Catalytic reactions of postconsumer waste over fluidized cracking catalyst for producing hydrocarbons. J. Molecular Catalysis AChemical 123 (172): 113-122.

Miskolczi, N (2014). Thermal and thermo catalytic degradation of high density polyethylene waste. $J$. Anal. Appl. Pyrolysis 72 (2): 235-242.

Nwadinigwe, CA (2012). Basic Principles of Organic Chemistry. WIPRO International. 101.

Nwadinigwe, CA; Alumona, TN (2017). Assessment of n-alkanes and acycylic isoprenoids (geochemical markers) in crudes. Egyptian J. Petrol. 1-6 http://do.doi org/10.1016/j.epe.2017.01.005.

Nwadinigwe, CA; Ezugwu, OK; Nwadinigwe, AO (2016). Assessment of aromatics to saturates ratios in the three Niger Delta Crudes. Egyptian J. Petrol. $1-4$

Oriji, AB; Ekpeti, E (2016). Natural gas Conditioning and Processing from Marginal fields using Modular Technology in Nigeria. Inter. J. Engineer. Res. Appli.. 6 (8): 40-46

Osueke, CO; Ofondu, IO (2011). Conversion of Waste Plastic Polyethylene to Fuel by means of Pyrolysis. J. Adv. Engineer. Sci. Technol.4 (1): 020-021

Smith, JM (1993). Chemical Engineering Kinetics (2 ${ }^{\text {nd }}$ Edition). McGraw Hill Kogakushha Ltd 5-12.

Sacchin, K.; and Singh, R.K (2011). Recovery of Hydrocarbon liquid from HDPE by Thermal Pyrolysis. Braz. J. Chem. Engineer. 28 (4): 659-667 